\title{
Can nocturnal hypertension predict cardiovascular risk?
}

\author{
This article was published in the following Dove Press journal: \\ Integrated Blood Pressure Control \\ 3 September 2009 \\ Number of times this article has been viewed
}

\author{
Oded Friedman' \\ Alexander G Logan² \\ 'Samuel Lunenfeld Research Institute, \\ Division of Nephrology, Mount \\ Sinai Hospital, ${ }^{2}$ Mount Sinai Hospital \\ and University Health Network \\ and Department of Medicine, \\ University of Toronto, Toronto, Canada
}

\begin{abstract}
Nocturnal hypertension and non-dipping of blood pressure during sleep are distinct entities that often occur together and are regarded as important harbingers of poor cardiovascular prognosis. This review addresses several aspects related to these blood pressure abnormalities including definitions, diagnostic limitations, pathogenesis and associated patient profiles, prognostic significance, and therapeutic strategies. Taken together, persistent nocturnal hypertension and non-dipping blood pressure pattern, perhaps secondary to abnormal renal sodium handling and/or altered nocturnal sympathovagal balance, are strongly associated with deaths, cardiovascular events, and progressive loss of renal function, independent of daytime and 24-hour blood pressure. Several pharmacological and non-pharmacological approaches may restore nocturnal blood pressure and circadian blood pressure rhythm to normal; however, whether this translates to a clinically meaningful reduction in unfavorable cardiovascular and renal consequences remains to be seen.
\end{abstract}

Keywords: blood pressure, sleep, nocturnal hypertension

\section{Introduction}

An appreciation of the normal sleep-wake cycle of blood pressure (BP) in humans, characterized by a nocturnal fall and diurnal rise, has been well established for several decades. ${ }^{1}$ Consequently, this has resulted in an increased awareness of nocturnal hypertension as well as various sleep BP pattern disturbances, gleaned non-invasively from the recordings provided by 24-hour ambulatory BP monitoring (ABPM).

\section{Definitions}

Nocturnal hypertension has been defined using various absolute nocturnal BP cut-offs. According to the American Heart Association Council on High Blood Pressure Research, nocturnal BP $<115 / 65$ is deemed optimal, $<120 / 70$ is deemed normal and $>125 / 75$ is deemed abnormal. ${ }^{2}$ Non-dipping is commonly defined as a $<10 \%$ fall in nocturnal BP relative to diurnal BP (ie, [daytime BP - night-time BP]/daytime $\mathrm{BP} \times 100 \%),{ }^{2}$ arithmetically equivalent to a night-to-day $\mathrm{BP}$ ratio $>0.9$. Non-dippers have been further subdivided into either attenuated dippers ( $\geq 0 \%$ but $<10 \%$ fall) or risers $(<0 \%$ fall). There is also a patient subset, situated at the opposite end of the dipping spectrum, referred to as extreme dippers ( $\geq 20 \%$ fall) that has been linked in some, although not all, studies with increased cardiovascular risk and mortality, perhaps related to nocturnal hypoperfusion and/or an exaggerated morning BP surge; ${ }^{3-6}$ however, this entity is not further discussed herein. Of note, although high nocturnal
Correspondence: Alexander G Logan Suite 435, Mount Sinai Hospital, 600 University Avenue, Toronto, Ontario, M5GIX5, Canada

$\mathrm{Tel}+\mathrm{I} 4 \mathrm{I} 6-586-5187$

$\mathrm{Fax}+\mid$ 416-586-5039

Email alogan@mtsinai.on.ca 
BP may be accompanied by a non-dipping pattern, both are not always concomitantly present and the pathophysiologic and clinical significance of each may differ. ${ }^{7}$

\section{Diagnostic limitations}

Over the years, a number of diagnostic limitations categorizing nocturnal BP and dipping status have been identified. First, there is no universal agreement on the definition of non-dipping. For example, in some reports, it is defined as higher sleep BP level than awake BP level, rather than the more commonly used definition of a $<10 \%$ fall in night-time BP. ${ }^{8,9}$ Second, studies of repeated ABPM have questioned the reproducibility of dipping status and diagnosing nocturnal hypertension using cut-off values, given the well-described phenomenon of regression to the mean. On repeated ABPM, expressing the decline in BP during sleep as a continuous variable (eg, percentage fall in nocturnal BP) was shown to be far more reproducible than its expression as a categorical variable (ie,using the traditionally adopted $10 \%$ cut-off), given a loss of information. ${ }^{10}$ This is particularly an issue for defining abnormalities of dipping status as definitions rest on a difference score of individual daytime and night-time BP levels. ${ }^{10-13}$ In a study of repeated ABPM, agreement in diagnosing nocturnal hypertension on the basis of two measurements was greater using an absolute nocturnal BP threshold value (Cohen's kappa $=0.485$ systolic $\mathrm{BP})$ rather than the percentage nocturnal BP fall (Cohen's kappa $=0.378$ systolic BP). ${ }^{14}$ Because of better metrics, nocturnal hypertension using threshold values was also a better predictor of left ventricular hypertrophy than non-dipping BP pattern. ${ }^{15}$ Third, the dipping pattern of systolic BP has been shown to be more reproducible than that of diastolic BP in several, ${ }^{12,16,17}$ although not all, ${ }^{18,19}$ studies. Fourth, the methods used to define the night-time period have varied from arbitrarily fixed clock times to self-reported sleep times using diary entries or even, polysomnographically verified sleep times. With respect to the arbitrarily fixed clock time method, one improvement has involved the use of narrow clock intervals to exclude the transition period from 0600 to $1000 \mathrm{~h}^{20}$ or 0700 to $1000 \mathrm{~h}^{21}$ in the morning and from 2000 to $0000 \mathrm{~h}^{20}$ or 2300 to $0100 \mathrm{~h}$ in the evening. ${ }^{21}$ Recently, it was shown that different definitions significantly affect the classification of nocturnal BP dipping and its relation to left ventricular mass index and urinary albumin excretion as indices of hypertensive target organ damage. ${ }^{12,22}$ Fifth, failing to account for night-time awakenings ${ }^{23}$ and daytime naps ${ }^{24}$ has been associated with misclassification of nocturnal hypertension. Additionally, variations in nocturnal body position and diurnal physical activity affect night-time and daytime BP. ${ }^{25,26}$ On balance, BP dipping status appears to be more influenced by night-time factors than by daytime physical activity. ${ }^{27}$ Sixth, nocturnal BP may be unreliable as a prognostic marker for cardiovascular events and deaths among subjects with perceived sleep deprivation $\geq 2$ hours during ABPM related to repeated cuff inflations. ${ }^{28}$ Finally, antihypertensive drug treatment and the timing of their administration can influence circadian BP profile. ${ }^{29,30}$

\section{Pathophysiology}

Although there have been several theories as to the pathogenesis of non-dipping including systemic and vascular inflammation and endothelial dysfunction, ${ }^{31}$ perhaps the two most cited explanations rest on abnormal renal sodium handling and disturbances in nocturnal autonomic or sympathovagal balance. Further, the association of nocturnal hypertension and non-dipping pattern with patient profiles provides further insights into mechanisms. Specifically, several patient characteristics have been associated with nocturnal hypertension and non-dipping BP pattern; not surprisingly, many of these states are associated with impaired renal capacity to excrete sodium and/or relative sympathoactivation.

\section{Abnormal renal sodium handling}

Many studies have shown an association between abnormal renal sodium handling and nocturnal hypertension and nondipping pattern of BP during sleep. In a recent study of a large group of African subjects, those with the lowest dayto-night ratios of urinary sodium excretion had significantly higher night-time systolic BP and lower systolic BP dipping in both unadjusted and adjusted analyses. ${ }^{16}$ The 'low daytime sodium excretors' excreted three times less sodium during the day than during the night, whereas the 'high daytime sodium excretors' had a sodium excretion rate that was $46 \%$ higher during the day than during the night, although total daily sodium excretion was equivalent in both groups. These findings are in accord with earlier, smaller studies conducted in hospitalized subjects. ${ }^{32-34}$ In a study of Japanese patients with essential hypertension, non-dippers on a high sodium diet had a significantly higher night-time systolic BP and mean arterial pressure (MAP) and showed no nocturnal decrease in BP compared to the dippers. ${ }^{32}$ Furthermore, night-time urinary sodium excretion was significantly greater in non-dippers than dippers and there was a strong positive relationship between night-to-day ratios of urinary sodium excretion and MAP. When the non-dippers were placed on a sodium-restricted diet, there was a significant fall in systolic 
$\mathrm{BP}$ and MAP in the non-dippers and there was no longer a significant difference in the night-to-day ratios of urinary sodium excretion between non-dippers and dippers. Given a greater antinatriuresis during the day in the non-dippers, higher nocturnal BP, as a result of pressure-natriuresis with near infinite gain over a wide range of urinary sodium excretion, may account for the greater proportion of urine sodium excreted at night to maintain total body sodium balance. ${ }^{35}$

Enhanced salt sensitivity of BP is often found in non-dippers ${ }^{35}$ and has been suggested as mediating nocturnal hypertension. ${ }^{33,34}$ Among black normotensive adolescents, a significantly greater proportion of non-dipping for MAP at $50 \%$ was identified in those deemed salt sensitive (defined as a $\geq 5 \mathrm{mmHg}$ BP difference between the high and low dietary salt states) as compared to $18.9 \%$ in those deemed salt resistant. ${ }^{36}$ Further, a Japanese study revealed that the nocturnal fall of BP from daytime to night-time was only significant among salt resistant hypertensives (defined as a $<10 \% \mathrm{BP}$ difference between the high and low dietary salt states) compared to their salt sensitive hypertensive counterparts. ${ }^{32}$ This has been attributed, in part, to a disturbed antinatriuretic response to postural change. Specifically, among hypertensive subjects, although the urinary sodium excretion rate was found to be significantly less in the upright than the supine position in both non-dippers and dippers, the difference was magnified in the non-dippers (despite no difference in postural BPs) because of an exaggerated reduction in upright sodium excretion. ${ }^{37}$ Exaggerated antinatriuretic effects of postural change may also contribute to the high prevalence of supine nocturnal hypertension in patients with autonomic failure, possibly related to increased sensitivity to changes in plasma volume with re-entry into the circulation of peripheral interstitial fluid accumulated during the day. ${ }^{38,39}$

The renal sodium regulatory mechanisms that give rise to nocturnal hypertension and non-dipping BP pattern remain unclear. In the case of chronic kidney disease, reduced ultrafiltration capacity likely accounts for the blunting of the nocturnal fall in BP along with enhanced natriuresis at night. ${ }^{40}$ However, many individuals with disturbed diurnal renal sodium excretion have normal glomerular function; ${ }^{16}$ in these instances, augmented tubular reabsorption of sodium during the day likely contributes to the genesis of the nocturnal BP and natriuretic abnormalities. ${ }^{35}$ In salt sensitive forms of hypertension such as primary aldosteronism, or patients with diabetes mellitus or metabolic syndrome, there is evidence of enhanced tubular sodium reabsorption that may account for non-dipping. ${ }^{34,40}$ Further evidence supporting a role for renal tubular sodium handling comes from studies of patients with essential hypertension showing a differential effect of hydrochlorothiazide, which inhibits sodium transport in the distal nephron, on nocturnal fall in BP in non-dippers compared to dippers, ${ }^{41,42}$ diuretic therapy restored the dipping BP pattern in non-dippers but had no effect in dippers. ${ }^{41}$

\section{Nocturnal sympathovagal imbalance}

Nocturnal sympathoexcitation has also been suggested as mediating nocturnal hypertension and non-dipping BP pattern. ${ }^{9,26}$ This is in contrast to the normal sleepwake cycle of sympathetic neural activity characterized by sympathoinhibition during sleep (particularly non-rapid-eye-movement sleep). ${ }^{43}$ In a cohort of normotensive and hypertensive subjects, non-dippers were observed to have a reduced night-time fall in urine catecholamine levels and heightened alpha-1-adrenergic receptor responsiveness to phenylephrine (but similar beta-adrenergic receptor responsiveness to isoproterenol), unlike dippers. ${ }^{44}$ A recent study found a significant inverse relationship between the degree of sympathetic activation, measured by muscle sympathetic nerve activity in the daytime, and the magnitude of night-time fall in $\mathrm{BP} .{ }^{45}$ In that report, the increase in sympathetic activity was greatest in subjects demonstrating an increase in nocturnal BP (risers). The findings are in accord with results of earlier studies demonstrating a higher mean daytime plasma norepinephrine level in risers ${ }^{9}$ and a greater reduction of night-time BP following administration of the alpha-adrenergic blocker, doxazosin. ${ }^{46}$ Several reports using power spectral analysis of heart rate variability suggest that a reduction in parasympathetic nervous system activity may also contribute to the non-dipping BP pattern in essential hypertension. ${ }^{47,48}$ The causal mechanism(s) leading to sustained nocturnal sympathetic augmentation is still poorly understood, but may include the insulin resistance state, which frequently accompanies sympathetic activation ${ }^{45,49}$ and innate or acquired susceptibility to the pressor effects of salt. ${ }^{50,51}$ However, changes in baroreflex sensitivity do not appear to account for abnormal dipping pattern as a study measuring it spontaneously or by the phenylephrine bolus technique found no significant difference between hypertensive dippers and non-dippers. ${ }^{52}$

\section{Associations}

A variety of factors including patient characteristics, clinical conditions, and dietary patterns have been reported to be associated with nocturnal hypertension and non-dipping. These links often provide some pathophysiologic insights. 


\section{Patient characteristics}

Multivariable assessment of a large cohort of untreated hypertensive men and women revealed a highly significant inverse linear correlation between the day-night systolic BP change and age in both sexes. ${ }^{53}$ The prevalence of the non-dipping BP pattern increased progressively with age, reaching $>40 \%$ in subjects $\geq 70$ years. Several studies have also noted increasing salt sensitivity of BP with increasing age, particularly among hypertensive patients, using provocative maneuvers to either contract or expand extracellular fluid volume. ${ }^{54,55}$ In fact, the presence of hypertension has been suggested as conferring a lower nocturnal fall in $\mathrm{BP},{ }^{56}$ although this has not been unanimously confirmed. ${ }^{57}$ Blacks have been consistently shown to have a greater frequency of both reduced nocturnal fall in $\mathrm{BP}^{58-62}$ and salt sensitivity of $\mathrm{BP}^{63,64}$ than whites. Blacks also have higher ambulatory heart rates and lower heart rate variability than non-blacks, possibly reflecting greater impairment in sympathovagal balance in this racial group. ${ }^{65}$ There does not appear to be a sex difference in the prevalence of non-dipping; ${ }^{53}$ nonetheless, several studies have shown more adverse health effects in hypertensive women with blunted nocturnal fall in BP. In contrast to men, they have a greater left ventricular mass index ${ }^{66,67}$ and are more likely to develop a cardiovascular complication. ${ }^{68}$

\section{Clinical conditions}

Several studies have shown that non-dipping is more commonly found in clinical conditions, including hypertension, diabetes mellitus, impaired glucose tolerance, renal disease, autonomic failure, disrupted sleep, and sleep apnea. Overall, it is estimated that approximately $22 \%$ of patients with essential hypertension have a non-dipping pattern. ${ }^{26}$ Among treated hypertensive patients, non-dipping may also be partly related to the absence of uniform 24-hour therapeutic antihypertensive coverage, perhaps especially in those treated with single morning doses and/or short-acting antihypertensive medications. ${ }^{29,69}$ We recently showed a significantly greater prevalence of non-dippers (particularly risers) in patients with refractory hypertension as compared to those with controlled hypertension and normal BP, matched for age, sex and $\mathrm{BMI},{ }^{70}$ with figures ranging from $66 \%$ to $79 \%$ reported by others. ${ }^{71,72}$ Previously, in a 3-month interventional trial of drug-resistant hypertension, patients randomized to receive antihypertensive treatment dictated by non-invasive hemodynamic measurements were found to have significantly lower $\mathrm{BP}$ and better BP control than those receiving specialist care alone and the differences were attributed to a significantly higher final diuretic dosing. ${ }^{73}$ Such data suggest that covert extracellular fluid volume expansion may be a dominant feature accounting for apparent treatment resistance in refractory hypertension and may also explain our parallel observation of greater attenuation of the nocturnal dipping pattern in such patients.

There is a higher prevalence of non-dipping among patients with diabetes mellitus, ${ }^{53,74}$ particularly among those with higher night-time than day-time readings. ${ }^{8}$ This finding does not appear to be a consequence of increased nocturnal awakenings from nocturia due to osmotic diuresis and/or neurogenic bladder. Among subjects reporting having taken an uninterrupted afternoon siesta, diabetics displayed a similar naptime BP decline to their night-time BP decline, which was blunted as compared to the non-diabetic controls. ${ }^{75}$ Several small studies have shown that insulin resistance in non-diabetic hypertensive subjects is also associated with a reduced nocturnal fall in BP. ${ }^{76-78}$ Mancia et al, however, did not find an increase in non-dipping pattern in patients with the metabolic syndrome, although less than one-third of these individuals had impaired glucose intolerance. ${ }^{79}$ Hermida et al recently reported a higher prevalence of non-dipping BP pattern in patients with the metabolic syndrome compared to those without this condition and they also had a higher BMI. ${ }^{80}$ Increased BMI, however, is not a characteristic feature of the non-dipping BP pattern as it was not significantly different among subjects dichotomized into 4 categories of the night-to-day ratio of systolic BP (extreme, normal, decreased, reverse) in a meta-analysis of several prospective population studies of 24-hour BP monitoring. ${ }^{81}$

Abnormal diurnal BP variability is present in patients with chronic kidney disease such that they are more likely non-dippers. ${ }^{82,83}$ For example, the mean nocturnal systolic BP change among patients with essential hypertension was found to be a decrease of $12.7 \mathrm{mmHg}$ compared to an increase of $2.7 \mathrm{mmHg}$ among hypertensive patients with renal parenchymal disease, despite matching for age, sex and 24-hour BP. ${ }^{84}$ Additionally, the decrease in unadjusted creatinine clearance following donor nephrectomy was found to correlate with the corresponding increase in the nightto-day BP ratio but not the 24-hour, daytime or night-time BP. ${ }^{85}$ Non-dipping has also been linked to accelerated loss of renal function. In a retrospective cohort study of outpatients attending a hospital clinic, non-dipping was associated with subsequent deterioration in renal function that was independent of baseline renal function, systolic BP load and other risk factors for renal impairment. ${ }^{86}$ Additionally, in a study of renal transplant recipients, non-dippers and risers had 
lower glomerular filtration rates, measured by iothalamate clearance, than dippers one year after transplantation; there was no difference in iothalamate glomerular filtration rates at the three week time point post-transplantation. ${ }^{87}$

Short habitual sleep duration may be associated with nondipping of nocturnal BP. In two separate studies, untreated hypertensive patients who were non-dippers were found to have significantly shorter durations of sleep by 0.3 hours in men and 0.5 hours in women (according to self-report) ${ }^{53}$ or by 81 minutes (according to wrist actigraphy), ${ }^{88}$ compared to their dipper counterparts; further multivariable analysis in one of these studies showed a positive linear correlation between the day-night systolic BP change and sleep duration. ${ }^{53}$ Moreover, poor sleep quality has also been suggested as being related to nocturnal hypertension. In a study of normotensive and hypertensive subjects with an apnea-hypopnea index $(\mathrm{AHI})<10$, the degree of nocturnal BP dipping was positively linked with the percentage of total sleep time occupied by stage 4 non-rapid eye movement sleep (reflecting depth of sleep) and negatively linked with the percentage of wake time following sleep onset (reflecting sleep fragmentation). ${ }^{89}$ Similar findings of less time spent in stage 4 non-rapid eye movement sleep and sleep fragmentation with micro/arousals along with other qualitative disturbances have also been reported by others. ${ }^{90-92}$ Notwithstanding the foregoing relations, sleep-disordered breathing, particularly obstructive sleep apnea-hypopnea (OSAH), has been strongly associated with non-dipping. ${ }^{93-96}$ Notably, the vast majority of mechanistic studies linking OSAH and hypertension are disproportionately represented by those implicating sympathoactivation (whether gauged by plasma or urine catecholamines or microneurography), independent of obesity. For example, a recent study involved normotensive subjects who were classified as lean or obese with or without OSAH (according to BMI, waist-to-hip ratio and AHI) and matched for age and sex. Relative to the nonOSAH lean group, muscle sympathetic nerve activity was significantly and similarly greater in both the OSAH lean group and in the non-OSAH obese group; the increase was even more pronounced in the OSAH obese group..$^{97}$

\section{Dietary patterns}

Several studies have recognized an increased prevalence of non-dipping status in obese patients, particularly in women. ${ }^{44,67,98}$ Salt sensitivity may underlie raised night-time $\mathrm{BP}$ in obese individuals. For example, in a study of obese and non-obese adolescents, when the obese group was changed from a high salt to a low salt diet there was a greater fall in their
BP compared to non-obese group. ${ }^{99}$ This increased sensitivity to dietary salt intake may be a manifestation of the hyperadrenergic state that is a feature of abdominal obesity and often ascribed to the central sympathetic effects of hyperinsulinemia and hyperleptinemia. ${ }^{100}$ The prevalence of OSAH, associated with increased likelihood of non-dipping pattern, ${ }^{93-96}$ also progressively increases as BMI and associated markers of obesity (eg, neck circumference, waist-to-hip ratio) increase. ${ }^{101}$

Dietary monovalent cation intake patterns, characterized by a high sodium or low potassium content, are also recognized as favoring a non-dipping BP pattern, particularly in salt sensitive individuals. ${ }^{102}$ The hypertensinogenic effects of a low potassium diet have been attributed, at least partly, to renal sodium retention. ${ }^{103}$ In the Dietary Approaches to Stop Hypertension (DASH) Trial, the BP of individuals randomly assigned to the 'combination' (DASH) diet that emphasized low fat dairy products, fruits and vegetables, thus containing high amounts of calcium and potassium, ${ }^{104}$ was significantly lower during the day and at night compared to the BP of those consuming the 'typical American' diet; however, the high quality (DASH) diet did not significantly affect dipping status. ${ }^{105}$ This is a surprising finding in view of the evidence from the same group of investigators that the DASH diet increased, thus improving, the pressure-natriuresis slope (ie, reduced salt-sensitivity). ${ }^{106}$ Possibly misclassification error from the use of a fixed clock method to determine dipping status might explain the negative result.

\section{Epidemiological studies}

Numerous observational studies have emerged addressing the prognostic significance of nocturnal hypertension and non-dipping BP pattern on mortality and cardiovascular disease.

\section{Considerations}

The presence of nocturnal hypertension in one individual but not the other would be expected to connote a greater 24-hour BP load if daytime BP levels were otherwise equivalent in the two individuals. Certainly, then, one would not be surprised to find a larger burden of hypertensive target organ damage in the former individual. What remains less clear is whether night-time BP is able to predict such vascular insult independent of daytime or 24-hour BP and perhaps further, whether its predictive ability is superior to that provided by daytime BP. If such an association is truly not spurious, several explanations could be held accountable. First, a proper interpretation of any observational study must be tempered by the potential 
for residual confounding. For example, if nocturnal hypertension were simply a marker for underlying illnesses linked to deaths and cardiovascular events, ${ }^{81,107}$ then any association identified with nocturnal hypertension may be inaccurately estimated if the given state and/or condition were either undefined or poorly defined. In addition, it may not be nocturnal hypertension per se but rather its underlying pathophysiologic state (eg, heightened sympathetic neural tone) that bestows vascular injury. Second, a cause-effect relation may indeed apply. The sleep state is typically associated with the minimum BP necessary to maintain organ perfusion; perhaps then, if also given a permissive hormonal milieu, susceptibility to vascular target organ damage may demonstrate circadian variability for a given BP load marked by an increase during sleep. ${ }^{108,109}$ Moreover, for the cerebrum, its vasculature may be less protected from hydrostatic (gravitational) forces when recumbent during sleep than when erect or sitting. ${ }^{110}$ Third, an effect-cause relation can be argued instead, particularly with cross-sectional and case-control studies. Specifically, nocturnal hypertension may simply reflect more extensive target organ damage placing the patient in a high-risk group, as opposed to having a direct effect. Fourth, in view of a narrower dispersion of nocturnal BP values compared to diurnal BP values, partly related to ambulatory physical activity, ${ }^{111}$ night-time BP would be expected to perform mathematically, but not necessarily biologically, better as a predictor than daytime BP. ${ }^{7}$

\section{Summary of findings}

On the basis of ABPM performed 1 to 5 years earlier, a case-control study of hypertensive subjects revealed a significantly lower nocturnal fall in BP among cases as compared to controls (based on the occurrence of a fatal or non-fatal cardiovascular event) but only in women, despite matching for several covariates including daytime BP. ${ }^{68}$ However, the vast majority of more recent studies focusing on the prognostic implications of nocturnal hypertension have been prospective cohort in design. Of course, there is also a robust body of literature that speaks to the association between nocturnal hypertension and a multitude of unfavorable structural (eg, cardiac chamber dilatation, ventricular hypertrophy, carotid intima-media thickening, silent lacunae, leukoaraiosis, brain microbleeds) and functional (eg, diastolic dysfunction) cardiovascular consequences. ${ }^{12-120}$ Tables 1 to 3 summarize the varied patient populations enrolled in and the methodological aspects and accompanying results of larger studies (sample size $>500$ ) that examined the clinical endpoints of all-cause mortality, cardiovascular mortality and/or cardiovascular morbidity. As evident, additional adjustments for either daytime or 24-hour BP were not uniformly made in such studies to allow for a determination

Table I Studies addressing independent prognostic significance of nocturnal blood pressure on all-cause mortality and/or cardiovascular mortality/morbidity

\begin{tabular}{|c|c|c|c|c|c|}
\hline Primary author & Year & Source of publication & $\begin{array}{l}\text { Country of primary } \\
\text { author's affiliation }\end{array}$ & Sample size & Study design \\
\hline \multirow[t]{2}{*}{ Ohkubo ${ }^{5,145}$} & $1997^{a}$ & Am J Hypertens & Japan & 1542 & Prospective cohort \\
\hline & 2002 & J Hypertens & & & \\
\hline Staessen ${ }^{6}$ & 1999 & JAMA & Belgium & 808 & Prospective cohort \\
\hline Dolan $^{122}$ & 2005 & Hypertension & Ireland & 5292 & Prospective cohort \\
\hline Ben-Dov ${ }^{121}$ & 2007 & Hypertension & Israel & 3957 & Prospective cohort \\
\hline Fagard $^{123}$ & 2008 & Hypertension & Belgium & 3468 & Meta-analysis \\
\hline Bjorklund ${ }^{146}$ & 2004 & J Hypertens & Sweden & 872 & Prospective cohort \\
\hline Kikuya $^{124}$ & 2005 & Hypertension & Japan & 1332 & Prospective cohort \\
\hline Ingelsson ${ }^{147}$ & 2006 & JAMA & Sweden & 951 & Prospective cohort \\
\hline Sega ${ }^{148}$ & 2005 & Circulation & Italy & 2051 & Prospective cohort \\
\hline Boggia $^{81}$ & 2007 & Lancet & Uruguay & 7458 & Meta-analysis \\
\hline Clement $^{149}$ & 2003 & N Engl J Med & Belgium & 1963 & Prospective cohort \\
\hline \multirow[t]{2}{*}{ Hansen $^{150,151}$} & 2005 & Hypertension & Denmark & 1700 & Prospective cohort \\
\hline & 2006 & Am J Hypertens & & & \\
\hline Verdecchia $^{152}$ & 1994 & Hypertension & Italy & 959 & Prospective cohort \\
\hline Brotman $^{153}$ & 2008 & Am J Hypertens & USA & 621 & Retrospective cohort \\
\hline
\end{tabular}

aPilot analysis. 
Table 2 Studies addressing independent prognostic significance of nocturnal blood pressure on all-cause mortality and/or cardiovascular mortality/morbidity

\begin{tabular}{|c|c|c|c|c|c|c|c|c|}
\hline $\begin{array}{l}\text { Primary } \\
\text { author }\end{array}$ & Age (yrs) & Male (\%) & BMI $\left(\mathrm{kg} / \mathrm{m}^{2}\right)$ & Current/exsmoker (\%) & DM (\%) & $\begin{array}{l}\text { Prevalent } \\
\text { CVD (\%) }\end{array}$ & $\begin{array}{l}\text { Mean daytime } \\
\text { BP }(\mathrm{mmHg})\end{array}$ & HTN (\%) \\
\hline Ohkubo ${ }^{5,145}$ & 61.6 & 36.6 & NA & 21.7 & NA & 4.5 & $128.6 / 76.1$ & 30.7 \\
\hline Staessen ${ }^{6}$ & 69.6 & 38.5 & 26.7 & 35.5 & NA & 26.6 & $15|.4 / 84|$. & 100 \\
\hline Dolan ${ }^{122}$ & 53.3 & 46.3 & 27.4 & 23.8 & 5.2 & 10.6 & |46. |/89.0 & 100 \\
\hline Ben-Dov ${ }^{121}$ & 55.0 & 47.0 & 27.2 & NA & 9.0 & NA & NA & 70.4 \\
\hline Fagard $^{123}$ & 60.8 & 44.8 & 27.7 & 13.7 & 8.4 & 0 & |43.5/87.| & 100 \\
\hline Bjorklund ${ }^{146}$ & 71.0 & 100 & 26.0 & 20.6 & 13.5 & 0 & NA & 30.1 \\
\hline Kikuya ${ }^{124}$ & 61.8 & 34.5 & NA & 20.4 & 17.4 & 5.6 & |28.9/76.| & 30.4 \\
\hline Ingelsson ${ }^{147}$ & 50.0 & 100 & 26.2 & 20.4 & 10.0 & 13.9 & |40.0/79.0 & 49.2 \\
\hline Sega ${ }^{148}$ & 52.9 & 52.8 & NA & 28.4 & 2.3 & 4.8 & $|29.0 / 8| .4$ & 44.2 \\
\hline Boggia $^{81}$ & 56.8 & 54.3 & NA & 29.3 & 7.5 & 8.3 & $|32.4 / 80|$. & 46.1 \\
\hline Clement $^{149}$ & 56.4 & 51.3 & 27.9 & 17.2 & 11.0 & 5.9 & |39.|/88.3 & 100 \\
\hline Hansen ${ }^{150,151}$ & 55.8 & 47.9 & 25.3 & 44.3 & 2.2 & 0 & $|3| .0 / 78.0$ & 8.9 \\
\hline Verdecchia ${ }^{152}$ & 52.9 & 49.8 & 27.0 & 23.7 & 9.8 & 3.1 & | $46.4 / 93.0$ & 100 \\
\hline Brotman $^{153}$ & 61.3 & 48.1 & 27.8 & 21.1 & 10.8 & 13.5 & NA & 74.4 \\
\hline
\end{tabular}

Abbreviations: BMI, body mass index; BP, blood pressure; CVD, cardiovascular disease; DM, diabetes mellitus; HTN, hypertension; NA, not available.

of the independent prognostic significance of night-time BP. Regardless, the bulk of the existing data suggests that nocturnal hypertension, whether expressed as a categorical or continuous predictor, is strongly associated with deaths and/or cardiovascular events. For example, in the Japanese general population, a 5\% attenuation in the nocturnal BP fall was associated with a $20 \%$ increase in cardiovascular mortality, even among individuals with a normal 24-hour BP (defined as $<135 / 80) .{ }^{5}$ In fact, several studies have also found that night-time BP, independent of daytime BP, may predict death and/or adverse cardiovascular outcomes better than daytime BP. ${ }^{6,81,121-124}$ For instance, among untreated hypertensive patients, an increase of $10 \mathrm{mmHg}$ in daytime or night-time $\mathrm{BP}$ was associated with hazard ratios (HRs) for cardiovascular mortality of 1.12 (daytime systolic) compared to 1.21 (nighttime systolic) and 1.04 (daytime diastolic; not significant) compared to 1.19 (night-time diastolic), after adjustment for the other BP. ${ }^{122}$ In a substudy of the Systolic Hypertension in Europe (Syst-Eur) trial, a 10-mmHg increase in night-time systolic BP was more predictive for all-cause deaths (adjusted HR 1.21), cardiovascular deaths (adjusted HR 1.21) and fatal and non-fatal cardiovascular events (adjusted HR: 1.26) than a comparable increase in daytime systolic BP (adjusted HRs 0.93, 1.03 and 0.94, respectively; not significant). ${ }^{6}$

The non-dipping BP pattern also predicted total mortality and cardiovascular events compared to the normal or extreme dipping pattern, independent of cohort and confounding variables and after adjustment for 24-hour BP, in a large meta-analysis of prospective studies from Europe, Asia and South America ${ }^{81}$ Similarly the night-to-day BP ratio treated as a continuous variable predicted all-cause mortality, again independent of 24-hour BP and confounding variables, in a smaller meta-analysis of only European prospective studies. ${ }^{123}$ Reverse dipping was the strongest predictor of total mortality and cardiovascular events in fully adjusted models. ${ }^{81}$ In this study, they were older, more frequently on antihypertensive medications and more likely to have a history of diabetes mellitus or previous cardiovascular disease, indicating that these individuals were at high risk. Compared to night-time $\mathrm{BP}$, however, non-dipping $\mathrm{BP}$ pattern and night-to-day BP ratio were less consistent predictors of cardiovascular mortality and non-fatal events in fully adjusted analyses, ${ }^{81,123}$ thus making them less important targets for interventions than absolute nocturnal BP level.

\section{Therapeutic strategies}

Whether greater effort should be expended on achieving night-time BP control and reversal of the non-dipping pattern over and above the attainment of daytime and 24-hour BP control so as to reap a greater reduction in deaths and cardiovascular events remains uncertain. Nonetheless, several strategies have been suggested as preferentially reducing nighttime BP with restoration of the normal circadian BP rhythm.

Both therapeutic lifestyle changes and pharmacological approaches are associated with conversion from non-dipper to dipper status. Two Japanese studies revealed that therapeutic interventions, namely dietary salt restriction and 
Table 3 Studies addressing independent prognostic significance of nocturnal blood pressure on all-cause mortality and/or cardiovascular mortality/morbidity

\begin{tabular}{|c|c|c|c|c|c|}
\hline $\begin{array}{l}\text { Primary } \\
\text { author }\end{array}$ & F/U (yrs) & $\begin{array}{l}\text { Ascertainment of } \\
\text { nighttime period }\end{array}$ & $\begin{array}{l}\text { Adjusted HR for } \\
\text { all-cause mortality }\end{array}$ & $\begin{array}{l}\text { Adjusted HR for } \\
\text { cardiovascular mortality }\end{array}$ & $\begin{array}{l}\text { Adjusted HR for } \\
\text { cardiovascular morbidity }\end{array}$ \\
\hline Ohkubo ${ }^{5,145}$ & $\begin{array}{l}5.1 \\
9.2\end{array}$ & Sleep diary & $\begin{array}{l}\text { Riser: } 2.12 \\
\text { Attenuated dipper: } 1.35 \text { (NS) }\end{array}$ & $\begin{array}{l}\text { Riser: } 4.97^{\mathrm{b}} \text { and } 3.79^{\mathrm{c}} \\
\text { Attenuated dipper: } 2.88^{\mathrm{b}} \text { and } 2.66^{\mathrm{c}} \\
\text { Non-dipper and } 24 \text {-hour } \\
\text { BP } \geq 135 / 80: 5.37 \\
\text { Non-dipper and } 24 \text {-hour } \\
\text { BP }<\text { I35/80: } 2.35\end{array}$ & NA \\
\hline Staessen ${ }^{6}$ & 4.4 & $0000-0600 \mathrm{~h}$ & $10 \mathrm{mmHg} \uparrow \mathrm{sBP}: 1.21^{\mathrm{b}}$ & $\begin{array}{l}10 \mathrm{mmHg} \uparrow \mathrm{sBP}: \\
\mathrm{I} .2 \mathrm{I}^{\mathrm{b}}(\mathrm{NS})\end{array}$ & $\begin{array}{l}10 \mathrm{mmHg} \uparrow \mathrm{sBP}: 1.26^{\mathrm{b}} \\
10 \% \uparrow \text { night-to-day } \\
\mathrm{sBP} \text { ratio: } 1.4 \mathrm{I}^{\mathrm{c}}\end{array}$ \\
\hline Dolan $^{122}$ & 7.9 & $0100-0600 \mathrm{~h}$ & $\begin{array}{l}10 \mathrm{mmHg} \uparrow \mathrm{sBP}: 1.18^{\mathrm{b}} \\
10 \mathrm{mmHg} \uparrow \mathrm{dBP}: 1.23^{\mathrm{b}}\end{array}$ & $\begin{array}{l}10 \mathrm{mmHg} \uparrow \mathrm{sBP}: 1.2 \mathrm{I}^{\mathrm{b}} \\
10 \mathrm{mmHg} \uparrow \mathrm{dBP}: 1.19^{\mathrm{b}}\end{array}$ & NA \\
\hline Ben-Dov' ${ }^{121}$ & 6.5 & Sleep diary & $\begin{array}{l}\text { Riser: } 1.96^{*} \\
\text { Attenuated dipper: } 1.30^{\mathrm{b}}\end{array}$ & NA & NA \\
\hline Fagard ${ }^{123}$ & 6.7 & $0000-0600 \mathrm{~h}$ & $\begin{array}{l}\text { I SD } \uparrow \mathrm{sBP}: \mathrm{I} .34^{\mathrm{b}} \\
\text { I SD } \uparrow \mathrm{dBP}: 1.28^{\mathrm{b}}\end{array}$ & $\begin{array}{l}\text { I SD } \uparrow \mathrm{sBP}: \mathrm{I} .34^{\mathrm{b}} \\
\text { I SD } \uparrow \mathrm{dBP}: 1.40^{\mathrm{b}}\end{array}$ & $\begin{array}{l}\text { I SD } \uparrow \mathrm{sBP}: 1.36^{\mathrm{b}} \\
\text { I SD } \uparrow \mathrm{dBP}: 1.2 \mathrm{I}^{\mathrm{b}}\end{array}$ \\
\hline Bjorklund ${ }^{146}$ & 6.6 & $0000-0600 \mathrm{~h}$ & NA & NA & $\begin{array}{l}\text { I SD } \uparrow \mathrm{sBP}: \mathrm{I} .18 \\
\text { I SD } \uparrow \mathrm{dBP}: 1.05 \text { (NS) }\end{array}$ \\
\hline Kikuya ${ }^{124}$ & 10.8 & Sleep diary & NA & $10 \mathrm{mmHg} \uparrow \mathrm{sBP}: \mathrm{I} .32^{*}$ & NA \\
\hline Ingelsson ${ }^{147}$ & 9.1 & $0000-0600 \mathrm{~h}$ & NA & NA & $\begin{array}{l}\text { I SD } \uparrow \mathrm{sBP}: 1.4 \mathrm{I}^{\mathrm{c}}(\mathrm{NS}) \\
\mathrm{I} \mathrm{SD} \uparrow \mathrm{dBP}: \mathrm{I} 47^{\mathrm{c}} \\
\text { (heart failure hospitalization) }\end{array}$ \\
\hline Sega ${ }^{148}$ & 10.9 & $2300-0700 \mathrm{~h}$ & $\begin{array}{l}10 \mathrm{mmHg} \uparrow \mathrm{sBP}: \mathrm{I} .42 \\
10 \mathrm{mmHg} \uparrow \mathrm{dBP}: \mathrm{I} .47\end{array}$ & $\begin{array}{l}10 \mathrm{mmHg} \uparrow \mathrm{sBP}: 1.75 \\
10 \mathrm{mmHg} \uparrow \mathrm{dBP}: 1.87\end{array}$ & NA \\
\hline Boggia $^{81}$ & 9.6 & $\begin{array}{l}0000-0600 \mathrm{~h} \\
\text { (Europe, South } \\
\text { America) } \\
2200-0400 \mathrm{~h} \text { (Asia) }\end{array}$ & $\begin{array}{l}\text { I SD } \uparrow \mathrm{sBP}: 1.22^{\mathrm{b}} \\
\text { I SD } \uparrow \mathrm{dBP}: 1.20^{*} \\
\text { Riser: I.56c } \\
\text { Attenuated dipper: } 1.19^{\mathrm{c}}\end{array}$ & $\begin{array}{l}\text { I SD } \uparrow \mathrm{sBP}: \text { I. } 22^{\mathrm{b}} \\
\text { I SD } \uparrow \mathrm{dBP}: 1.24^{\mathrm{b}} \\
\text { Riser: I.45c } \\
\text { Attenuated dipper: I.08c (NS) }\end{array}$ & $\begin{array}{l}\text { I SD } \uparrow \mathrm{sBP}: 1.2 \mathrm{I}^{\mathrm{b}} \\
\text { I SD } \uparrow \mathrm{dBP}: 1.20^{\mathrm{b}} \\
\text { Riser: } 1.30^{\mathrm{c}} \\
\text { Attenuated dipper: } 1.05^{\mathrm{c}} \text { (NS) }\end{array}$ \\
\hline Clement $^{149}$ & 5.0 & $0000-0600 \mathrm{~h}$ & $\begin{array}{l}\text { I SD } \uparrow \mathrm{sBP}: \text { I.06 (NS) } \\
\text { I SD } \uparrow \mathrm{dBP}: 1.07 \text { (NS) }\end{array}$ & NA & $\begin{array}{l}\text { I SD } \uparrow \mathrm{sBP}: \mathrm{I} .27 \\
\text { I SD } \uparrow \mathrm{dBP}: 1.18 \text { (NS) }\end{array}$ \\
\hline Hansen ${ }^{150,151}$ & 9.5 & Diary & $\begin{array}{l}10 \mathrm{mmHg} \uparrow \mathrm{sBP}: 1.19 \\
10 \mathrm{mmHg} \uparrow \mathrm{dBP}: 1.35\end{array}$ & $\begin{array}{l}10 \mathrm{mmHg} \uparrow \mathrm{sBP}: \mathrm{I} .4 \mathrm{I} \\
10 \mathrm{mmHg} \uparrow \mathrm{dBP}: \mathrm{I} .85\end{array}$ & $\begin{array}{l}10 \mathrm{mmHg} \uparrow \mathrm{sBP}: 1.27 \\
10 \mathrm{mmHg} \uparrow \mathrm{dBP}: 1.54 \\
\text { Non-dipper and daytime } \\
\mathrm{BP} \geq 135 / 85: 1.68^{\mathrm{c}} \\
\text { Non-dipper and daytime } \\
\mathrm{BP}<135 / 85: 0.58^{\mathrm{c}}(\mathrm{NS})\end{array}$ \\
\hline Verdecchia $^{152}$ & 3.2 & $1000-0600 \mathrm{~h}$ & NA & NA & $\begin{array}{l}\text { Non-dipper and male: I.04 (NS) } \\
\text { Non-dipper and female: } 6.26\end{array}$ \\
\hline Brotman $^{153}$ & 6.3 & $2300-0600 \mathrm{~h}$ & Non-dipper: I.47c & NA & NA \\
\hline
\end{tabular}

ancludes fatal and non-fatal cardiovascular events unless otherwise specified.

bIncludes adjustment for daytime blood pressure.

Includes adjustment for 24-hour blood pressure.

Abbreviations: BP, blood pressure; dBP, diastolic blood pressure; F/U, follow-up; HR, hazard ratio; NA, not available; NS, not significant; sBP, systolic blood pressure; SD, standard deviation.

diuretic therapy, which reduce total body sodium content were able to restore the normal dipping pattern of $\mathrm{BP}$ in salt sensitive hypertensive patients (defined as a $\geq 10 \%$ BP difference between the high and low dietary salt states) unlike their salt resistant hypertensive counterparts. ${ }^{32,41}$ Similarly, intensified ultrafiltration in hemodialysis patients initially identified as risers led to a conversion to either dipper or attenuated dipper status, in the majority of cases. ${ }^{125}$ In addition to dietary sodium, among 58 black normotensive adolescents, a 3-week high potassium diet was able to revert salt sensitive (defined as $a \geq 5 \mathrm{mmHg}$ BP difference between the high and low dietary salt states) individuals originally deemed non-dippers to 
dippers, which was unlike both their salt resistant counterparts as well as the usual diet control group in which nearly all such individuals remained non-dippers. ${ }^{126}$ Correspondingly, among normotensive men, potassium supplementation was found to dose-dependently suppress salt sensitivity (defined as an increase in mean $\mathrm{BP} \geq 3 \mathrm{mmHg}$ with salt loading), particularly in blacks who had a greater frequency and severity of salt sensitivity. ${ }^{63}$ A significant reduction of night-time BP following a 1-year multidisciplinary weight loss program was observed among normotensive obese women. ${ }^{127}$ Moreover, in morbidly obese (body mass index BMI $>35 \mathrm{~kg} / \mathrm{m}^{2}$ ) hypertensive patients, bariatric surgery restored the normal circadian rhythm in non-dippers from a nocturnal systolic BP fall of $4 \%$ to $16.4 \% .{ }^{128}$ In parallel, following the institution of a 20 -week weight loss program, a decreased salt sensitivity of BP was observed but only in those who had successfully lost more than $1 \mathrm{~kg}$ of body weight. ${ }^{99}$

In the area of nocturnal sympathoexcitation, a significant reduction of nocturnal BP following night-time dosing of an alpha-1-adrenergic blocker in hypertensive patients was identified but in non-dippers only. ${ }^{129}$ This differential effect, however, has been observed with other classes of antihypertensive agents, arguing against the specificity of the response. ${ }^{42,130}$ Pharmacokinetic and pharmacodynamic differences between various antihypertensive medications and their times of administration ('chronotherapy') may be important factors in determining nocturnal antihypertensive effects. For example, despite equivalent daytime BP control, differential antihypertensive effects on night-time BP were demonstrated between a long-acting calcium channel blocker and a similarly long-acting angiotensin converting enzyme inhibitor in a group of elderly hypertensive patients. ${ }^{131}$ Nocturnal dosing of antihypertensive agents has also been associated with conversion from attenuated dipper or riser to dipper status in both controlled and refractory hypertensive patient populations. ${ }^{130,132-135}$ Uncontrolled short-term studies have revealed reductions in night-time BP readings along with transition from non-dipper to dipper status among normotensive and hypertensive subjects following nocturnal application of therapeutic continuous positive airway pressure (CPAP), ${ }^{136-138}$ which has been associated with sympathoinhibition unlike nocturnal application of subtherapeutic CPAP or oxygen. ${ }^{139}$ In patients with end-stage renal disease, renal transplantation has been associated with a significant lowering of the prevalence of non-dipping from $73 \%$ within the first year after transplantation to $27 \%$ following the first year after transplantation, independent of 24-hour BP and concomitant medication changes, ${ }^{140}$ with the nocturnal BP fall correlating with renal allograft function. ${ }^{87}$ Finally, in randomized parallel and crossover trials, nocturnal administration of exogenous melatonin was associated with a significant reduction of night-time BP, especially among non-dippers, unlike daytime BP and in some cases, this could not be entirely explained on the basis of an improvement in sleep. ${ }^{141-143}$ Non-dipping in subjects with type 2 diabetes mellitus has been found to relate more closely to post-prandial glycemic excursions, rather than fasting hyperglycemia. ${ }^{144}$ However, whether improvements in glycemic control as well as sleep quality and duration translate into normalization of the circadian BP rhythm remains to be seen.

\section{Conclusions}

Awareness of the normal sleep-wake cycle of BP has resulted in an increasing appreciation for the significance of nondipping, a concept often used to construe nocturnal hypertension. Notwithstanding various limitations, principally related to its reproducibility, the identification of nocturnal hypertension has been shown to predict deaths and/or adverse cardiovascular events both independent of and often superior to daytime BP. Several patient profiles have been associated with its occurrence (eg, older age, black race, diabetes mellitus, obesity, chronic kidney disease, sleep-related disturbances); moreover, many of these states are associated with sympathoexcitation and/or augmented salt sensitivity suggesting a common pathophysiologic basis. Further, a number of therapeutic strategies (eg, dietary salt restriction, diuretic therapy, dietary potassium liberalization, weight loss, chronotherapy, nocturnal CPAP) have demonstrated restorative capacity for the normal circadian BP rhythm. Nevertheless, whether greater effort expended on achievement of night-time $\mathrm{BP}$ control above and beyond daytime BP results in a greater improvement in patient outcomes remains to be seen.

\section{Acknowledgments}

Funding from Grant-in-Aid \#NA-5327 from the Heart and Stroke Foundation of Ontario.

\section{Disclosures}

The authors declare no conflicts of interest.

\section{References}

1. Millar-Craig MW, Bishop CN, Raftery EB. Circadian variation of blood-pressure. Lancet. 1978;1:795-797.

2. Pickering TG, Hall JE, Appel LJ, et al. Recommendations for blood pressure measurement in humans and experimental animals: Part 1 : blood pressure measurement in humans: a statement for professionals from the Subcommittee of Professional and Public Education of the American Heart Association Council on High Blood Pressure Research. Hypertension. 2005;45:142-161. 
3. Kario K, Pickering TG, Umeda Y, et al. Morning surge in blood pressure as a predictor of silent and clinical cerebrovascular disease in elderly hypertensives: a prospective study. Circulation. 2003;107:1401-1406.

4. Metoki H, Ohkubo T, Kikuya M, et al. Prognostic significance for stroke of a morning pressor surge and a nocturnal blood pressure decline: the Ohasama study. Hypertension. 2006;47:149-154.

5. Ohkubo T, Hozawa A, Yamaguchi J, et al. Prognostic significance of the nocturnal decline in blood pressure in individuals with and without high 24-h blood pressure: the Ohasama study. J Hypertens. 2002;20:2183-2189.

6. Staessen JA, Thijs L, Fagard R, et al. Predicting cardiovascular risk using conventional vs ambulatory blood pressure in older patients with systolic hypertension. Systolic Hypertension in Europe Trial Investigators. JAMA. 1999;282:539-546.

7. Redon J, Lurbe E. Nocturnal blood pressure versus nondipping pattern: what do they mean? Hypertension. 2008;51:41-42.

8. Bjorklund K, Lind L, Andren B, Lithell H. The majority of nondipping men do not have increased cardiovascular risk: a population-based study. J Hypertens. 2002;20:1501-1506.

9. Kario K, Mitsuhashi T, Shimada K. Neurohumoral characteristics of older hypertensive patients with abnormal nocturnal blood pressure dipping. Am J Hypertens. 2002;15:531-537.

10. Chaves H, Campello de Souza FM, Krieger EM. The reproducibility of dipping status: beyond the cutoff points. Blood Press Monit. 2005;10:201-205

11. Cuspidi C, Meani S, Salerno M, et al. Reproducibility of nocturnal blood pressure fall in early phases of untreated essential hypertension: a prospective observational study. J Hum Hypertens. 2004;18:503-509.

12. Henskens LH, Kroon AA, van Oostenbrugge RJ, et al. Different classifications of nocturnal blood pressure dipping affect the prevalence of dippers and nondippers and the relation with target-organ damage. J Hypertens. 2008;26:691-698.

13. Manning G, Rushton L, Donnelly R, Millar-Craig MW. Variability of diurnal changes in ambulatory blood pressure and nocturnal dipping status in untreated hypertensive and normotensive subjects. Am J Hypertens. 2000;13:1035-1038.

14. White WB, Larocca GM. Improving the utility of the nocturnal hypertension definition by using absolute sleep blood pressure rather than the "dipping" proportion. Am J Cardiol. 2003;92:1439-1441.

15. Perez-Lloret S, Toblli JE, Cardinali DP, et al. Nocturnal hypertension defined by fixed cut-off limits is a better predictor of left ventricular hypertrophy than non-dipping. Int J Cardiol. 2008;127:387-389.

16. Bankir L, Bochud M, Maillard M, et al. Nighttime blood pressure and nocturnal dipping are associated with daytime urinary sodium excretion in African subjects. Hypertension. 2008;51:891-898.

17. Omboni S, Parati G, Palatini P, et al. Reproducibility and clinical value of nocturnal hypotension: prospective evidence from the SAMPLE study. Study on Ambulatory Monitoring of Pressure and Lisinopril Evaluation. J Hypertens. 1998;16:733-738.

18. James MA, Fotherby MD, Potter JF. Reproducibility of the circadian systolic blood pressure variation in the elderly. J Hypertens. 1995;13:1097-1103.

19. Staessen J, Bulpitt CJ, O’Brien E, et al. The diurnal blood pressure profile. A population study. Am J Hypertens. 1992;5:386-392.

20. Fagard R, Brguljan J, Thijs L, Staessen J. Prediction of the actual awake and asleep blood pressures by various methods of $24 \mathrm{~h}$ pressure analysis. J Hypertens. 1996;14:557-563.

21. van Ittersum FJ, Ijzerman RG, Stehouwer CD, Donker AJ. Analysis of twenty-four-hour ambulatory blood pressure monitoring: what time period to assess blood pressures during waking and sleeping? J Hypertens. 1995;13:1053-1058

22. Verdecchia P, Angeli F, Sardone M, et al. Is the definition of daytime and nighttime blood pressure prognostically relevant? Blood Press Monit. 2008;13:153-155.

23. Lenz MC, Martinez D. Awakenings change results of nighttime ambulatory blood pressure monitoring. Blood Press Monit. 2007;12:9-15.
24. Ben-Dov IZ, Bursztyn M. Daytime sleeping and night-time urinating obscure normal dipping. Nephrol Dial Transplant. 2006;21: 226-227.

25. Cavelaars M, Tulen JH, van Bemmel JH, van den Meiracker AH. Physical activity, dipping and haemodynamics. J Hypertens. 2004;22: 2303-2309.

26. Pickering TG, Kario K. Nocturnal non-dipping: what does it augur? Curr Opin Nephrol Hypertens. 2001,10:611-616.

27. Mann S, Craig MW, Melville DI, et al. Physical activity and the circadian rhythm of blood pressure. Clin Sci (Lond). 1979;57 Suppl 5: 291S-294S.

28. Verdecchia P, Angeli F, Borgioni C, et al. Ambulatory blood pressure and cardiovascular outcome in relation to perceived sleep deprivation. Hypertension. 2007;49:777-783.

29. Chonan K, Hashimoto J, Ohkubo T, et al. Insufficient duration of action of antihypertensive drugs mediates high blood pressure in the morning in hypertensive population: the Ohasama study. Clin Exp Hypertens. 2002;24:261-275.

30. Lemmer B. The importance of circadian rhythms on drug response in hypertension and coronary heart disease - from mice and man. Pharmacol Ther. 2006;111:629-651.

31. Birkenhager AM, van den Meiracker AH. Causes and consequences of a non-dipping blood pressure profile. Neth J Med. 2007;65:127-131.

32. Uzu T, Ishikawa K, Fujii T, et al. Sodium restriction shifts circadian rhythm of blood pressure from nondipper to dipper in essential hypertension. Circulation. 1997;96:1859-1862.

33. Uzu T, Kazembe FS, Ishikawa K, et al. High sodium sensitivity implicates nocturnal hypertension in essential hypertension. Hypertension. 1996;28:139-142.

34. Uzu T, Kimura G, Yamauchi A, et al. Enhanced sodium sensitivity and disturbed circadian rhythm of blood pressure in essential hypertension. J Hypertens. 2006;24:1627-1632.

35. Sachdeva A, Weder AB. Nocturnal sodium excretion, blood pressure dipping, and sodium sensitivity. Hypertension. 2006;48:527-533.

36. Wilson DK, Sica DA, Miller SB. Ambulatory blood pressure nondipping status in salt-sensitive and salt-resistant black adolescents. Am J Hypertens. 1999, 12:159-165.

37. Uzu T, Takeji M, Yamauchi A, Kimura G. Circadian rhythm and postural change in natriuresis in non-dipper type of essential hypertension. J Hum Hypertens. 2001;15:323-327.

38. Wilcox CS, Puritz R, Lightman SL, et al. Plasma volume regulation in patients with progressive autonomic failure during changes in salt intake or posture. J Lab Clin Med. 1984;104:331-339.

39. Okamoto LE, Gqamboa A, Shibao C, et al. Nocturnal blood pressure dipping in the hypertension of autonomic failure. Hypertension. 2009;53:363-369.

40. Kimura G. Kidney and circadian blood pressure rhythm. Hypertension. 2008;51:827-828

41. Uzu T, Kimura G. Diuretics shift circadian rhythm of blood pressure from nondipper to dipper in essential hypertension. Circulation. 1999;100:1635-1638

42. Weir MR, Reisin E, Falkner B, et al. Nocturnal reduction of blood pressure and the antihypertensive response to a diuretic or angiotensin converting enzyme inhibitor in obese hypertensive patients. TROPHY Study Group. Am J Hypertens. 1998;11:914-920.

43. Somers VK, Dyken ME, Mark AL, Abboud FM. Sympathetic-nerve activity during sleep in normal subjects. N Engl J Med. 1993;328: 303-307.

44. Sherwood A, Steffen PR, Blumenthal JA, et al. Nighttime blood pressure dipping: the role of the sympathetic nervous system. Am J Hypertens. 2002;15:111-118.

45. Grassi G, Seravalle G, Quarti-Trevano F, et al. Adrenergic, metabolic, and reflex abnormalities in reverse and extreme dipper hypertensives. Hypertension. 2008;52:925-931.

46. Ebata H, Hojo Y, Ikeda U, et al. Differential effects of an alpha 1-blocker (doxazosin) on diurnal blood pressure variation in dipper and non-dipper type hypertension. Hypertens Res. 1995;18:125-130. 
47. Kohara K, Nishida W, Maguchi M, Hiwada K. Autonomic nervous function in non-dipper essential hypertensive subjects. Evaluation by power spectral analysis of heart rate variability. Hypertension. 1995,26:808-814.

48. Nakano Y, Oshima T, Ozono R, et al. Non-dipper phenomenon in essential hypertension is related to blunted nocturnal rise and fall of sympatho-vagal nervous activity and progress in retinopathy. Auton Neurosci. 2001;88:181-186.

49. Mancia G, Grassi G, Giannattasio C, Seravalle G. Sympathetic activation in the pathogenesis of hypertension and progression of organ damage. Hypertension. 1999;34:724-728.

50. Okuguchi T, Osanai T, Kamada T, et al. Significance of sympathetic nervous system in sodium-induced nocturnal hypertension. J Hypertens. 1999;17:947-957.

51. Yo Y, Nagano M, Moriguchi A, et al. Predominance of nocturnal sympathetic nervous activity in salt-sensitive normotensive subjects. Am J Hypertens. 1996;9:726-731.

52. Vaile JC, Stallard TJ, al-Ani M, et al. Sleep and blood pressure spontaneous baroreflex sensitivity in dippers and non-dippers. JHypertens. 1996;14:1427-1432.

53. Schillaci G, Verdecchia P, Borgioni C, et al. Predictors of diurnal blood pressure changes in 2042 subjects with essential hypertension. J Hypertens. 1996;14:1167-1173.

54. Luft FC, Fineberg NS, Weinberger MH. The influence of age on renal function and renin and aldosterone responses to sodium-volume expansion and contraction in normotensive and mildly hypertensive humans. Am J Hypertens. 1992;5:520-528.

55. Weinberger MH, Fineberg NS. Sodium and volume sensitivity of blood pressure. Age and pressure change over time. Hypertension. 1991;18:67-71.

56. Morfis L, Howes LG. Nocturnal fall in blood pressure in the elderly is related to presence of hypertension and not age. Blood Press. 1997;6:274-278.

57. Pickering TG, Harshfield GA, Kleinert HD, et al. Blood pressure during normal daily activities, sleep, and exercise. Comparison of values in normal and hypertensive subjects. JAMA. 1982;247:992-996.

58. Agyemang C, Bhopal R, Bruijnzeels M, Redekop WK. Does nocturnal blood pressure fall in people of African and South Asian descent differ from that in European white populations? A systematic review and meta-analysis. J Hypertens. 2005;23:913-920.

59. Gretler DD, Fumo MT, Nelson KS, Murphy MB. Ethnic differences in circadian hemodynamic profile. Am J Hypertens. 1994;7:7-14.

60. Hebert LA, Agarwal G, Ladson-Wofford SE, et al. Nocturnal blood pressure in treated hypertensive African Americans Compared to treated hypertensive European Americans. J Am Soc Nephrol. 1996;7:2130-2134.

61. Hyman DJ, Ogbonnaya K, Taylor AA, et al. Ethnic differences in nocturnal blood pressure decline in treated hypertensives. $\mathrm{Am} \mathrm{J}$ Hypertens. 2000;13:884-891.

62. Profant J, Dimsdale JE. Race and diurnal blood pressure patterns. A review and meta-analysis. Hypertension. 1999;33:1099-1104.

63. Morris RC Jr, Sebastian A, Forman A, et al. Normotensive salt sensitivity: effects of race and dietary potassium. Hypertension. 1999;33:18-23.

64. Weinberger MH: Salt sensitivity of blood pressure in humans. Hypertension. 1996;27:481-490.

65. Jehn ML, Brotman DJ, Appel LJ. Racial differences in diurnal blood pressure and heart rate patterns: results from the Dietary Approaches to Stop Hypertension (DASH) trial. Arch Intern Med. 2008;168:996-1002.

66. Schmieder RE, Rockstroh JK, Aepfelbacher F, et al. Gender-specific cardiovascular adaptation due to circadian blood pressure variations in essential hypertension. Am J Hypertens. 1995;8:1160-1166.

67. Verdecchia P, Schillaci G, Borgioni C, et al. Gender, day-night blood pressure changes, and left ventricular mass in essential hypertension. Dippers and peakers. Am J Hypertens. 1995;8:193-196.

68. Verdecchia P, Schillaci G, Gatteschi C, et al. Blunted nocturnal fall in blood pressure in hypertensive women with future cardiovascular morbid events. Circulation. 1993;88:986-992.
69. Hermida RC, Calvo C, Ayala DE, et al. Relationship between physical activity and blood pressure in dipper and non-dipper hypertensive patients. J Hypertens. 2002;20:1097-1104.

70. Friedman O, Logan AG. Nocturnal blood pressure profiles among normotensive, controlled hypertensive and refractory hypertensive subjects. Can J Cardiol. In press. 2008.

71. Hermida RC, Ayala DE, Fernandez JR, Calvo C. Chronotherapy improves blood pressure control and reverts the nondipper pattern in patients with resistant hypertension. Hypertension. 2008;51:69-76.

72. Muxfeldt ES, Bloch KV, Nogueira Ada R, Salles GF. True resistant hypertension: is it possible to be recognized in the office? $\mathrm{Am} \mathrm{J}$ Hypertens. 2005;18:1534-1540.

73. Taler SJ, Textor SC, Augustine JE. Resistant hypertension: comparing hemodynamic management to specialist care. Hypertension. 2002;39:982-988.

74. Fogari R, Zoppi A, Malamani GD, et al. Ambulatory blood pressure monitoring in normotensive and hypertensive type 2 diabetes. Prevalence of impaired diurnal blood pressure patterns. Am J Hypertens. 1993;6:1-7.

75. Perk G, Mekler J, Ben Ishay D, Bursztyn M. Non-dipping in diabetic patients: insights from the siesta. J Hum Hypertens. 2002;16:435-438.

76. Anan F, Takahashi N, Ooie T, et al. Role of insulin resistance in nondipper essential hypertensive patients. Hypertens Res. 2003;26:669-676.

77. Chen JW, Jen SL, Lee WL, et al. Differential glucose tolerance in dipper and nondipper essential hypertension: the implications of circadian blood pressure regulation on glucose tolerance in hypertension. Diabetes Care. 1998;21:1743-1748.

78. Suzuki M, Kimura Y, Tsushima M, Harano Y. Association of insulin resistance with salt sensitivity and nocturnal fall of blood pressure. Hypertension. 2000;35:864-868.

79. Mancia G, Bombelli M, Corrao G, et al. Metabolic syndrome in the Pressioni Arteriose Monitorate E Loro Associazioni (PAMELA) study: daily life blood pressure, cardiac damage, and prognosis. Hypertension. 2007;49:40-47.

80. Hermida RC, Chayan L, Ayala DE, et al. Association of metabolic syndrome and blood pressure nondipping profile in untreated hypertension. Am J Hypertens. 2009;22:307-313.

81. Boggia J, Li Y, Thijs L, et al. Prognostic accuracy of day versus night ambulatory blood pressure: a cohort study. Lancet. 2007;370:1219-1229.

82. Baumgart $\mathrm{P}$, Walger $\mathrm{P}$, Gemen $\mathrm{S}$, et al. Blood pressure elevation during the night in chronic renal failure, hemodialysis and after renal transplantation. Nephron. 1991;57:293-298.

83. Farmer CK, Goldsmith DJ, Cox J, et al. An investigation of the effect of advancing uraemia, renal replacement therapy and renal transplantation on blood pressure diurnal variability. Nephrol Dial Transplant. 1997;12:2301-2307.

84. Portaluppi F, Montanari L, Massari M, et al. Loss of nocturnal decline of blood pressure in hypertension due to chronic renal failure. Am J Hypertens. 1991;4:20-26.

85. Goto N, Uchida K, Morozumi K, et al. Circadian blood pressure rhythm is disturbed by nephrectomy. Hypertens Res. 2005;28:301-306.

86. Davidson MB, Hix JK, Vidt DG, Brotman DJ. Association of impaired diurnal blood pressure variation with a subsequent decline in glomerular filtration rate. Arch Intern Med. 2006;166:846-852.

87. Wadei HM, Amer H, Taler SJ, et al. Diurnal blood pressure changes one year after kidney transplantation: relationship to allograft function, histology, and resistive index. J Am Soc Nephrol. 2007;18: $1607-1615$.

88. Mansoor GA. Sleep actigraphy in hypertensive patients with the 'nondipper' blood pressure profile. J Hum Hypertens. 2002;16:237-242.

89. Loredo JS, Nelesen R, Ancoli-Israel S, Dimsdale JE. Sleep quality and blood pressure dipping in normal adults. Sleep. 2004;27:1097-1103.

90. Pedulla M, Silvestri R, Lasco A, et al. Sleep structure in essential hypertensive patients: differences between dippers and non-dippers. Blood Press. 1995;4:232-237. 
91. Silva AP, Moreira C, Bicho M, et al. Nocturnal sleep quality and circadian blood pressure variation. Rev Port Cardiol. 2000;19:991-1005.

92. Yilmaz MB, Yalta K, Turgut OO, et al. Sleep quality among relatively younger patients with initial diagnosis of hypertension: dippers versus non-dippers. Blood. Press. 2007;16:101-105.

93. Davies CW, Crosby JH, Mullins RL, et al. Case-control study of 24 hour ambulatory blood pressure in patients with obstructive sleep apnoea and normal matched control subjects. Thorax. 2000;55:736-740.

94. Nagata K, Osada N, Shimazaki M, et al. Diurnal blood pressure variation in patients with sleep apnea syndrome. Hypertens Res. 2008;31:185-191.

95. Pankow W, Nabe B, Lies A, et al. Influence of sleep apnea on 24-hour blood pressure. Chest. 1997;112:1253-1258.

96. Portaluppi F, Provini F, Cortelli P, et al. Undiagnosed sleep-disordered breathing among male nondippers with essential hypertension. J Hypertens. 1997; 15:1227-1233.

97. Grassi G, Facchini A, Trevano FQ, et al. Obstructive sleep apnea-dependent and -independent adrenergic activation in obesity. Hypertension. 2005;46:321-325.

98. Kotsis V, Stabouli S, Bouldin M, et al. Impact of obesity on 24-hour ambulatory blood pressure and hypertension. Hypertension. 2005;45:602-607.

99. Rocchini AP, Key J, Bondie D, et al. The effect of weight loss on the sensitivity of blood pressure to sodium in obese adolescents. $N$ Engl J Med. 1989;321:580-585.

100. Rahmouni K, Correia ML, Haynes WG, Mark AL. Obesity-associated hypertension: new insights into mechanisms. Hypertension. 2005;45:9-14.

101. Young T, Skatrud J, Peppard PE. Risk factors for obstructive sleep apnea in adults. JAMA. 2004;291:2013-2016.

102. Sica DA. What are the influences of salt, potassium, the sympathetic nervous system, and the renin-angiotensin system on the circadian variation in blood pressure? Blood Press Monit. 1999;4 Suppl 2: S9-S16.

103. Adrogue HJ, Madias NE. Sodium and potassium in the pathogenesis of hypertension. N Engl J Med. 2007;356:1966-1978.

104. Mente A, Irvine EJ, Honey RJ, Logan AG. Urinary potassium is a clinically useful test to detect a poor quality diet. J Nutr. 2009;139:743-749.

105. Moore TJ, Vollmer WM, Appel LJ, et al. Effect of dietary patterns on ambulatory blood pressure : results from the Dietary Approaches to Stop Hypertension (DASH) Trial. DASH Collaborative Research Group. Hypertension. 1999;34:472-477.

106. Akita S, Sacks FM, Svetkey LP, et al. Effects of the Dietary Approaches to Stop Hypertension (DASH) diet on the pressure-natriuresis relationship. Hypertension. 2003;42:8-13.

107. Nakano S, Fukuda M, Hotta F, et al. Reversed circadian blood pressure rhythm is associated with occurrences of both fatal and nonfatal vascular events in NIDDM subjects. Diabetes. 1998;47:1501-1506.

108. Brandenberger G, Follenius M, Goichot B, et al. Twenty-fourhour profiles of plasma renin activity in relation to the sleep-wake cycle. J Hypertens. 1994;12:277-283.

109. Morgan TO, Brunner HR, Aubert JF, et al. Cardiac hypertrophy depends upon sleep blood pressure: a study in rats. $J$ Hypertens. 2000;18:445-451.

110. O'Rourke MF. Brain microbleeds, amyloid plaques, intellectual deterioration, and arterial stiffness. Hypertension. 2008;51:e20; author reply e21.

111. Kario K, Schwartz JE, Pickering TG. Ambulatory physical activity as a determinant of diurnal blood pressure variation. Hypertension. 1999;34:685-691.

112. Andersen NH, Poulsen SH, Poulsen PL, et al. Left ventricular dysfunction in hypertensive patients with Type 2 diabetes mellitus. Diabet Med. 2005;22:1218-1225.
113. Cuspidi C, Macca G, Sampieri L, et al. Target organ damage and non-dipping pattern defined by two sessions of ambulatory blood pressure monitoring in recently diagnosed essential hypertensive patients. J Hypertens. 2001;19:1539-1545.

114. Cuspidi C, Meani S, Salerno M, et al. Cardiovascular target organ damage in essential hypertensives with or without reproducible nocturnal fall in blood pressure. J Hypertens. 2004;22:273-280.

115. Ferrara AL, Pasanisi F, Crivaro M, et al. Cardiovascular abnormalities in never-treated hypertensives according to nondipper status. Am J Hypertens. 1998;11:1352-1357.

116. Henskens LH, van Oostenbrugge RJ, Kroon AA, et al. Brain microbleeds are associated with ambulatory blood pressure levels in a hypertensive population. Hypertension. 2008;51:62-68.

117. Kario K, Matsuo T, Kobayashi H, et al. Nocturnal fall of blood pressure and silent cerebrovascular damage in elderly hypertensive patients. Advanced silent cerebrovascular damage in extreme dippers. Hypertension. 1996;27:130-135.

118. Morfis L, Butler SP, Shnier RC, Howes LG. Nocturnal blood pressure predicts left ventricular mass index in normotensive elderly. Blood Press. 2002;11:18-21.

119. Schwartz GL, Bailey KR, Mosley T, et al. Association of ambulatory blood pressure with ischemic brain injury. Hypertension. 2007;49:1228-1234.

120. Verdecchia P, Schillaci G, Guerrieri M, et al. Circadian blood pressure changes and left ventricular hypertrophy in essential hypertension. Circulation. 1990;81:528-536.

121. Ben-Dov IZ, Kark JD, Ben-Ishay D, et al. Predictors of all-cause mortality in clinical ambulatory monitoring: unique aspects of blood pressure during sleep. Hypertension. 2007;49:1235-1241.

122. Dolan E, Stanton A, Thijs L, et al. Superiority of ambulatory over clinic blood pressure measurement in predicting mortality: the Dublin outcome study. Hypertension. 2005;46:156-161.

123. Fagard RH, Celis H, Thijs L, et al. Daytime and nighttime blood pressure as predictors of death and cause-specific cardiovascular events in hypertension. Hypertension. 2008;51:55-61.

124. Kikuya M, Ohkubo T, Asayama K, et al. Ambulatory blood pressure and 10-year risk of cardiovascular and noncardiovascular mortality: the Ohasama study. Hypertension. 2005;45:240-245.

125. Kursat S, Aysel S, Alici T, Tezcan UK. Blood pressure and ejection fraction changes due to ultrafiltration in hemodialysis. $J$ Nephrol. 2006;19:84-90.

126. Wilson DK, Sica DA, Miller SB. Effects of potassium on blood pressure in salt-sensitive and salt-resistant black adolescents. Hypertension. 1999;34:181-186.

127. Esposito K, Marfella R, Gualdiero P, et al. Sympathovagal balance, nighttime blood pressure, and QT intervals in normotensive obese women. Obes Res. 2003;11:653-659.

128. Czupryniak L, Strzelczyk J, Pawlowski M, Loba J. Circadian blood pressure variation in morbidly obese hypertensive patients undergoing gastric bypass surgery. Am J Hypertens. 2005;18:446-451.

129. Kario K, Schwartz JE, Pickering TG: Changes of nocturnal blood pressure dipping status in hypertensives by nighttime dosing of alpha-adrenergic blocker, doxazosin: results from the HALT study. Hypertension. 2000;35:787-794.

130. Hermida RC, Calvo C, Ayala DE, et al. Treatment of non-dipper hypertension with bedtime administration of valsartan. J Hypertens. 2005;23:1913-1922.

131. Eguchi K, Kario K, Shimada K. Effects of long-acting ACE inhibitor (temocapril) and long-acting Ca channel blocker (amlodipine) on 24-h ambulatory BP in elderly hypertensive patients. J Hum Hypertens. 2001;15:643-648.

132. Hermida RC, Ayala DE, Calvo C, et al. Effects of time of day of treatment on ambulatory blood pressure pattern of patients with resistant hypertension. Hypertension. 2005;46:1053-1059.

133. Hermida RC, Ayala DE, Fernandez JR, Calvo C. Comparison of the efficacy of morning versus evening administration of telmisartan in essential hypertension. Hypertension. 2007;50:715-722. 
134. Minutolo R, Gabbai FB, Borrelli S, et al. Changing the timing of antihypertensive therapy to reduce nocturnal blood pressure in CKD: an 8-week uncontrolled trial. Am J Kidney Dis. 2007;50:908-917.

135. Qiu Y, Zhu J, Tao Q, et al. Captopril administered at night restores the diurnal blood pressure rhythm in adequately controlled, nondipping hypertensives. Cardiovasc Drugs Ther. 2005;19:189-195.

136. Akashiba T, Minemura H, Yamamoto H, et al. Nasal continuous positive airway pressure changes blood pressure "non-dippers" to "dippers" in patients with obstructive sleep apnea. Sleep. 1999;22: 849-853.

137. Minemura H, Akashiba T, Yamamoto H, et al. Acute effects of nasal continuous positive airway pressure on 24-hour blood pressure and catecholamines in patients with obstructive sleep apnea. Intern Med. 1998;37:1009-1013.

138. Voogel AJ, van Steenwijk RP, Karemaker JM, van Montfrans GA. Effects of treatment of obstructive sleep apnea on circadian hemodynamics. J Auton Nerv Syst. 1999;77:177-183.

139. Mills PJ, Kennedy BP, Loredo JS, et al. Effects of nasal continuous positive airway pressure and oxygen supplementation on norepinephrine kinetics and cardiovascular responses in obstructive sleep apnea. J Appl Physiol. 2006;100:343-348.

140. Gatzka CD, Schobel HP, Klingbeil AU, et al. Normalization of circadian blood pressure profiles after renal transplantation. Transplantation. 1995;59:1270-1274.

141. Cagnacci A, Cannoletta M, Renzi A, et al. Prolonged melatonin administration decreases nocturnal blood pressure in women. $\mathrm{Am} J$ Hypertens. 2005;18:1614-1618.

142. Grossman E, Laudon M, Yalcin R, et al. Melatonin reduces night blood pressure in patients with nocturnal hypertension. Am J Med 2006;119:898-902.

143. Scheer FA, Van Montfrans GA, van Someren EJ, et al. Daily nighttime melatonin reduces blood pressure in male patients with essential hypertension. Hypertension. 2004;43:192-197.
144. Pistrosch F, Reissmann E, Wildbrett J, et al. Relationship between diurnal blood pressure variation and diurnal blood glucose levels in type 2 diabetic patients. Am J Hypertens. 2007;20:541-545.

145. Ohkubo T, Imai Y, Tsuji I, et al. Relation between nocturnal decline in blood pressure and mortality. The Ohasama Study. Am J Hypertens. 1997; 10:1201-1207.

146. Bjorklund K, Lind L, Zethelius B, et al. Prognostic significance of 24-h ambulatory blood pressure characteristics for cardiovascular morbidity in a population of elderly men. J Hypertens. 2004;22:1691-1697.

147. Ingelsson E, Bjorklund-Bodegard K, Lind L, et al. Diurnal blood pressure pattern and risk of congestive heart failure. JAMA. 2006;295:2859-2866.

148. Sega R, Facchetti R, Bombelli M, et al. Prognostic value of ambulatory and home blood pressures compared with office blood pressure in the general population: follow-up results from the Pressioni Arteriose Monitorate e Loro Associazioni (PAMELA) study. Circulation. 2005;111:1777-1783.

149. Clement DL, De Buyzere ML, De Bacquer DA, et al. Prognostic value of ambulatory blood-pressure recordings in patients with treated hypertension. N Engl J Med. 2003;348:2407-2415.

150. Hansen TW, Jeppesen J, Rasmussen S, et al. Ambulatory blood pressure and mortality: a population-based study. Hypertension. 2005;45:499-504.

151. Hansen TW, Jeppesen J, Rasmussen S, et al. Ambulatory blood pressure monitoring and risk of cardiovascular disease: a population based study. Am J Hypertens. 2006;19:243-250.

152. Verdecchia P, Porcellati C, Schillaci G, et al. Ambulatory blood pressure. An independent predictor of prognosis in essential hypertension. Hypertension. 1994;24:793-801.

153. Brotman DJ, Davidson MB, Boumitri M, Vidt DG. Impaired diurnal blood pressure variation and all-cause mortality. Am J Hypertens. 2008;21:92-97.
Integrated Blood Pressure Control

\section{Publish your work in this journal}

Integrated Blood Pressure Control is an international, peer-reviewed open-access journal focusing on the integrated approach to managing hypertension and risk reduction. Treating the patient and comorbidities together with diet and lifestyle modification and optimizing healthcare resources through a multidisciplinary team approach constitute key

\section{Dovepress}

features of the journal. This journal is indexed on American Chemical Society's Chemical Abstracts Service (CAS). The manuscript management system is completely online and includes a very quick and fair peerreview system, which is all easy to use. Visit http://www.dovepress.com/ testimonials.php to read real quotes from published authors. 